\title{
Geomagnetic solar flare effects: a review
}

\author{
Juan José Curto* \\ Observatori de l'Ebre (OE) CSIC - Universitat Ramon Llull, 43520 Roquetes, Spain
}

Received 3 December 2019 / Accepted 15 May 2020

\begin{abstract}
Solar flare effects (Sfe) are rapid variations in the Earth's magnetic field and are related to the enhancement of the amount of radiation produced during Solar flare events. They mainly appear in the Earth's sunlit hemisphere at the same time as the flare observation and have a crochet-like shape. Much progress has been made since Carrington's first observations in 1859 which are considered to represent the first direct evidence of the connection between the Sun and the Earth's environment but there is still much to discover. In this paper, we review state-of-the-art developments and the advances made in the knowledge concerning Sfe phenomena while also looking at the challenges that lie ahead. First, we offer a historical approach with a comprehensive description that allows for a better understanding of the main characteristics of Sfe. This frames specific topics like the puzzling reversed-Sfe or the nighttime Sfe. The role played by the Service of Rapid Magnetic variations (SRMV) is also assessed, followed by a discussion of the main current limiting factors in the process of detection and proposed ways to overcome challenges such as by creating an automatic detection method. The paper clarifies some aspects related to the geo-effectiveness of the solar flares producing magnetic disturbances. The importance of the global modelling studies covering critical aspects needed to understand this Sun-Earth system is assessed. Also, we provide an overview of the temporal evolution of the electric currents producing Sfe. The importance of key subjects such as the dynamic aspects of Sfe is developed in another section. Finally, estimations of the size of large flares using ionospheric and magnetic data are reviewed as well as the prospects of these large flare events putting technological systems in danger.
\end{abstract}

Keywords: solar flare / solar flare effects / history / review / crochet

\section{History}

\subsection{Discovery of Sfe}

The first time a geomagnetic variation was observed as a result of a solar flare was during the course of the great solar event of September 1, 1859. Mr. Richard C. Carrington observed areas of white light in the solar disk at $11 \mathrm{~h} 18 \mathrm{~m}$ that day, and later he noticed that geomagnetic records at Kew Observatory simultaneously showed a sudden jump in the three geomagnetic elements (Carrington, 1860; Stewart, 1861; Chapman \& Bartels, 1940; Mitra, 1952). Mr. Richard Hodgson also independently observed the flare and compiled a report (Hodgson, 1860) which was published side-by-side to that of R.C. Carrington in the Monthly Notices of the Royal Astronomical Society. Unfortunately, this historical event did not attract the attention of most scientists of that time who tended to consider the coincidence as fortuitous. Only a few of them, such as Balfour Stewart (1861) or Carrington himself, inferred the connection. It was

\footnotetext{
*Corresponding author: jjcurto@obsebre.es
}

not until much later, when radio-communication disturbances were noticed, that this interpretation of the event was unanimously accepted as a Sun-Earth relationship.

The existence of electric currents circulating in a layer of the high atmosphere had already been considered by Stewart in 1882 to explain the diurnal variation of the geomagnetic field. However, a series of important historical events including the success in radio communications by Marconi (1899), the prediction of the existence of the ionosphere by both Kennelly (1902) and Heaviside (1902), and the ionosphere probes of Appleton \& Barnett (1925) and Breit \& Tuve (1925) opened the door to the studies of ionosphere physics and wireless communications engineering.

The phenomena of high frequency radio signals fading out (short wave fade-out or SWF) were first observed by Mögel between 1927 and 1930. Mögel (1930) found an increase in electron content due to an excessive ionization in the ionosphere during a "fade-out".

During the 1930s, Dellinger (1935) carefully studied the fading of high-frequency radio waves ("fade-out") over Europe and North America. For the event of May 12, 1935, 
$11 \mathrm{~h} 57 \mathrm{~m}-12 \mathrm{~h} 00 \mathrm{~m}$, he discovered a correspondence with solar activity. He was able to confirm, with several examples, that the fade-out followed the solar chromospheric flares.

The effect of a geomagnetic variation produced by a solar flare as a phenomenon associated with a fading radio signal was found by Fleming (1936) in the event of August 25, 1936. McNish (1937a, 1937b) was the first to draw the current maps corresponding to the geomagnetic variation during solar flares, and he also found a sudden variation in the telluric currents. In these works, Fleming and McNish interpreted the geomagnetic effect of solar flares as being due to the fact that ultraviolet light emitted in the solar chromosphere at the time of a solar eruption produces an additional atmospheric ionization, which intensifies the normal diurnal variation of the geomagnetic field, although only in the hemisphere illuminated by the sun. The types of geomagnetic effects of solar flares and their relationship with the Sq field (Solar quiet = diurnal geomagnetic variation on the days of least magnetic activity; Matsushita \& Campbell, 1967) were examined by Imamiti $(1938,1940)$ at different observatories. The results of this test reaffirmed McNish's conclusion. His interpretation that the geomagnetic effects of solar flares are linked to an increase in $\mathrm{Sq}$ has been held true for a long time.

On the other hand, analyses of many events with the sudden fading of radio waves in relation to the associated geophysical phenomena were carried out (Berkner \& Wells, 1937a; Dellinger, 1937). The vertical structure of the ionosphere was discussed by Berkner \& Wells (1937b) with the help of automatic multi-frequency ionospheric sounding techniques. These authors showed that the effects of the flares were large in region $\mathrm{D}$ and lower, but still appreciable, in region $\mathrm{E}$. In the F-region they were insignificant. In addition, they found that the predominant increase in ionization in these cases occurred below $100 \mathrm{~km}$ and extended to the E-region. They concluded that it must be there that the geomagnetic effects and simultaneous ionospheric effects observed were caused. Since then, most of the studies of the ionospheric effects of solar flares have mostly concentrated on the effects within the D-region. Thus, Gavrilov et al. (2018) recently studied the interrelation and space-temporal distribution of geophysical disturbances induced by a flare and their influence on the accuracy of the positioning of global navigation satellite systems. He suggested that the effect of magnetic crochet that arises when the conductivity in the D-region changes can serve as an indicator of changes in the properties of the lower ionosphere as a whole. The term "crochet" from the French word for hook - that is its common shape, (Fig. 1) - was the initial name of this phenomena but, little by little, it has been substituted by the term "solar flare effect" (Sfe), moving the emphasis from the morphology of the effect (seen on the magnetograms) to the location of the cause. In this work, both terms will be used.

In addition to SWF, several types of ionospheric effects (now called sudden ionospheric disturbances (SIDs)) have been found: sudden cosmic noise absorption (SCNA), sudden enhancement of atmospherics (SEA) and sudden phase anomalies (SPA). Thanks to the study of these phenomena, the structure of the low ionosphere is now understood much better.

As for the geomagnetic effects of solar flares as a transitory phenomenon, the effects of electromagnetic induction within the Earth and self-induction in the ionosphere had already been noted. Rikitake (1950) showed that about one third of the

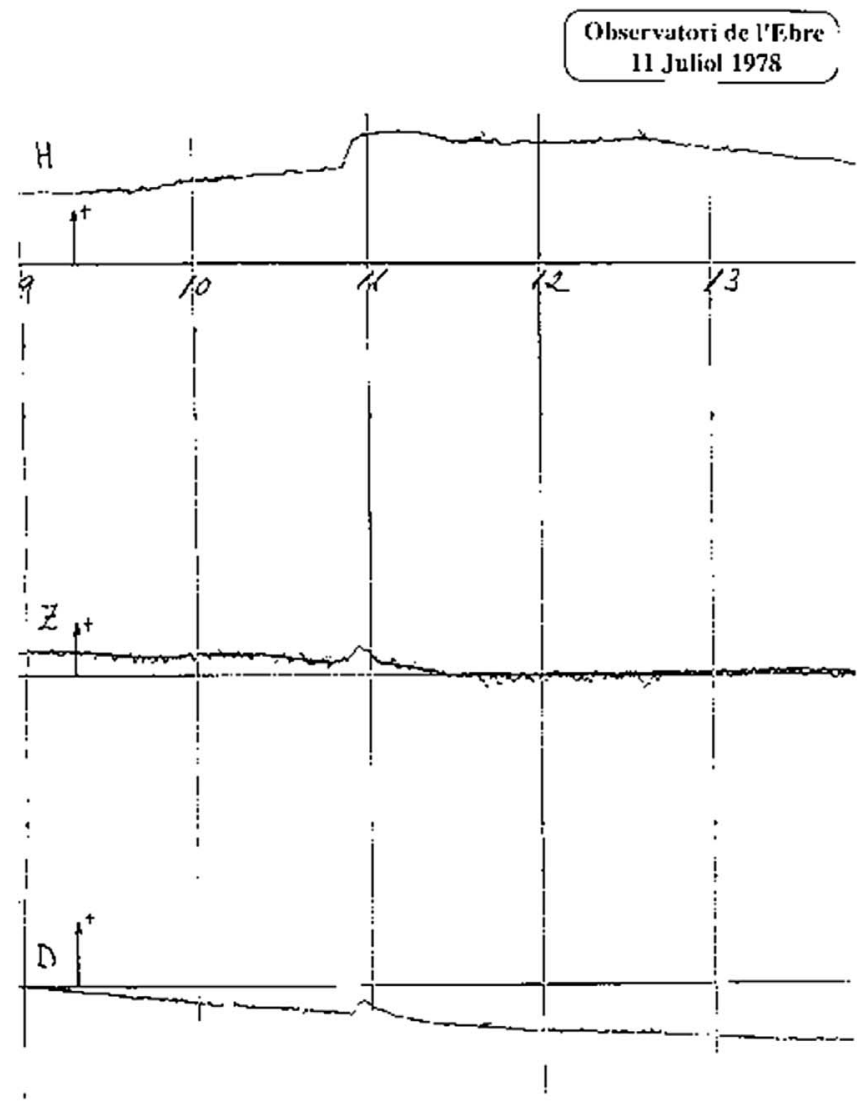

Fig. 1. Fragment of a magnetogram recorded at Ebro Observatory displaying an Sfe which happened close to 11:00 (LT).

geomagnetic changes observed on land originated in the interior of the Earth, and this relationship was almost the same as that for the case of $\mathrm{Sq}$ and other transient geomagnetic variations. This ratio was confirmed in several works (Siscoe et al., 1968; Tanskanen et al., 2001; Marsal et al., 2016) but modulated by the rapidity of the magnetic change. Nagata (1952) showed that the time of establishment of the geomagnetic effect of solar flares is explainable from an electromagnetic induction in the ionosphere, when its electrical conductivity suddenly increases at the time of a solar flare.

At that time, the possibility that the origin of the effects of solar flares were the X-rays of the solar corona emitted simultaneously with the intense visible light and ultraviolet rays of the solar chromosphere was also considered. Thus, Friedman \& Chubb (1954) pointed out the quantitative difficulty of justifying the large excess of ionization in the D-region during a solar flare with only the electrons produced by the $\mathrm{H} \alpha$ emission of the Lyman series.

The effect of a solar flare in the F-region was first seen by Dieminger \& Geisweid (1950) in the great event of November 19, 1949, accompanied by an extraordinary increase in the intensity of cosmic rays. Subsequent analyses on the F2 layer with more events were carried out by Minnis \& Bazzard (1958) proving the statistical significance of the association of these two phenomena.

Dodson \& Hedeman (1958) noted that Sfe tended to be associated with intense flares in the solar limb observed in the $\mathrm{H} \alpha$ line of the Balmer series. 
The development of rockets made it possible to explore the outer space of Earth and many discoveries soon followed. The dynamo currents of the ionosphere were located in the E-region (Maple et al., 1950; Singer et al., 1951; Cahill, 1959). Solar $\mathrm{X}$-rays were detected for the first time in a period of low solar activity in 1949 (Friedman et al., 1951) and later it was observed that, during a solar flare, the intensity of X-ray flux increased considerably compared to light in other wavelengths. Friedman et al. concluded, after his direct measurements of solar radiation in space vehicles, that the main ionizing agent of the effects of solar flare was X-rays with wavelengths between 1 and $100 \AA$.

\subsection{First global studies}

Comparing the geomagnetic change during a solar flare with respect to the $\mathrm{Sq}$ vector in several magnetic observatories, Volland \& Taubenhein (1958) found that the geomagnetic effects of a solar flare were not a mere increase in normal Sq. They assumed that the systematic difference in the forms that current systems regularly adopted (the geomagnetic effects of solar flare with respect to the Sq variation) could be attributed to differences in the level of the layers that supported the currents of both systems. According to their estimate, the contribution of the electric currents of layers D and E during a geomagnetic effect of solar flare were practically the same. Another important fact was that, in certain cases, the current system Sfe was delayed between $15^{\circ}$ and $30^{\circ}$ in longitude behind the current system Sq. Subsequent studies (i.e., Curto et al., 1994a) confirmed these facts.

During 1957, the International Geophysical Year, it was provided valuable magnetic data from around the world. Using these data, Veldkamp \& Van Sabben (1960), Yasuhara \& Maeda (1961), and Van Sabben (1961) showed some examples of the ionospheric current systems responsible for the geomagnetic effects of solar flares. Veldkamp and Van Sabben interpreted them as residing in a layer lower than the ordinary dynamo current, thus supporting Volland and Taubenheim's ideas. Van Sabben (1961, 1968) obtained a quantitative description of Sfe. He also discussed the asymmetry of the current circuits with respect to the magnetic equator. The current vortex of the northern hemisphere was generally centred west of the current vortex of the southern hemisphere and was relatively more intense in the northern summer than in the southern summer. The current systems of the diurnal variation at the time of the Sfe showed the same difference in length between the North and South vortices. However, these centres were located at a lower latitude and farther west than those corresponding to the Sfe currents.

\subsection{Transients in the development of the Sfe}

Ohshio et al. (1963), Ohshio (1964), Greenfield \& Venkateswaran (1968), and Richmond \& Venkateswaran (1971) attempted to trace the temporal evolution of the currents for the different stages in the progress of a flare.

Ohshio (1964) studied the temporal phase shift between the maximum phase of crochets worldwide using 15 selected cases from the International Geophysical Year. For each case, he determined the distribution of the moment of the maximum intensity of the Sfe at different observatories from around the world. The time at which maximum development was reached was not simultaneous around the world; the delay increased, the further it was from the subsolar point. In the study of these cases, he found a change in the position of the main focus on the longitude-latitude plane (vortex migration) as the flares progressed. The position was closer to the focus of the $\mathrm{Sq}$ at the time of the maximum phase.

Greenfield \& Venkateswaran (1968) observed that the change in the forms of the currents that they deduced from several Sfe was mostly the result of the temporal variation of the spectrum of the incident radiation of the flare in an ionosphere with variable winds in height. They also presented evidence that the spectrum of flare intensified in the initial stages of the event of August 28, 1966, which they analysed. For this same event, they found an Sfe vortex migration similar to that described by Ohshio.

Regarding the theoretical investigation of the effects of induction, Roy $(1977,1979)$ studied the transients of the currents with a two-layer superimposed model (in regions D and E) and analytically calculated the effects of mutual induction between them. Compared to the model of single layer, constant conductivity and effects only from self-induction prepared by Rikitake \& Yukutake (1962), Roy was able to explain in a somewhat better way certain morphological characteristics of the transients of the currents during a flare, such as the movement of the focus in the longitude-latitude plane as the flare progressed.

\section{Correlation with other physical phenomena}

\subsection{Sfe and solar flares}

Nagata (1966) studied the temporal phase shift between the maximum phases of the currents of crochets and those of other ionospheric disturbances. However, a shortage of stations in the ionospheric observation network and uncertainty in the measurements meant he could not reach any conclusions. Regarding the amplitudes, he found a direct relationship qualitatively between the amplitudes of the Sfe and those of other SIDs. However, he could not establish a quantitative relationship due to the wide dispersion in the magnitudes of both.

Sastri \& Murthy (1975a) investigated the relationship between the characteristics of Sfe and those of X-rays and microwave bursts of the sun. For the studied cases (Sfe observed at Kodaikanal during 1966-1971), they found that large increases in flow were necessary $\left(120-130 \times 10^{-5} \mathrm{erg} \mathrm{cm}^{-2} \mathrm{~s}^{-1}\right.$ in the band $0.5-3 \AA$ ) to produce an Sfe. This contrasted with other SID phenomena with significantly lower triggering levels (1-3 $\times 10^{-5} \mathrm{erg} \mathrm{cm}^{-2} \mathrm{~s}^{-1}$ in the same band) (Deshpande et al., 1972). The fact that the other SIDs are much more sensitive to flares with X-radiation than the Sfe would explain the relative low frequency of occurrence of Sfe compared to other SIDs. They found a linear correlation between the peak intensity of the X-rays in the band 1-20 $\AA$ and the amplitude of the Sfe, in contrast to other SIDs such as SPAs and SCNAs where the correlation is exponential. They also found a correlation between the amplitude of the Sfe and the radio "bursts" coming from the sun in the $2000-3700 \mathrm{MHz}$ frequency range. The Sfe were primarily associated with the spectral-type radio bursts A (the peak of flow increases with the frequency). They also differed from the SWF, SCNA, SPA, SEA, and SES that 
were associated with those of type-C (the variation of the flow peak with the frequency is maximum in the covered frequency range) and $M$ (the variation of the peak of zigzag flow). However, Sastri (1977) showed that the association between magnetic crochet and solar microwave "bursts" depends on the frequency of observation (in the range of $1-17 \mathrm{GHz}$ ). While at over $4995 \mathrm{MHz}$ magnetic crochets are better correlated with impulse-type bursts (Das Gupta \& Sarkar, 1971), over $2000 \mathrm{MHz}$ the correlation is better with those of complex-type ones (Sastri, 1977).

In line with the characterization of Sfe according to the nature of the flares, there are studies by Subrahmanyan (1964) on relativistic flares (ground level enhancement (GLE)) and Pintér (1967) and Sastri et al. (1975) on proton flares (polar cap absorption (PCA) events). Comparing these effects with the Sfe produced by flares that we could call normal (not relativistic or protonic ones), they found greater amplitudes in the Sfe produced by GLE-generating flares and longer establishment times and total duration in the Sfe produced by PCA-generating flares.

\subsection{Sfe and equatorial electrojet}

Nagata (1952) showed that the amplitude of the $H$-component of a magnetic crochet is abnormally large at Huancayo and other low latitude stations. Rastogi et al. (1965) found that this equatorial increase in amplitude is more pronounced in the American zone than in India. Srivastava (1974) observed that in the event of May 3, 1973, the $H$-component of the $\mathrm{Sfe}$ in equatorial stations was relatively low compared to that seen at the stations outside the electrojet. This was attributed to the presence at that time of a counterelectrojet current. Rastogi et al. (1975) and Sastri (1975c) found another case, that of July 6,1968, in which, within the area of the magnetic equator, there was not only a decrease in the amplitude of the Sfe but even a change of direction. Rangarajan \& Rastogi (1981), using a similar case (June 4, 1980), estimated the longitudinal extension of the reversion phenomenon as being less than $45^{\circ}$. Rastogi et al. (1999) studied solar flare effects for the Indo-USSR chain of magnetic observatories extending from the magnetic latitudes $0^{\circ}-45^{\circ} \mathrm{N}$ during strong and normal electrojet periods, during a counter electrojet period and also during a partial counter electrojet period. Finally, in Villante \& Regi (2008), in agreement with model predictions for normal electrojet conditions given by Rastogi et al. (1999) and Rastogi (2001, 2003), the Sfe studied offered a maximum manifestation in the central part of the day and at equatorial latitudes, where they were basically characterised by positive $H$ variations.

\subsection{Sfe and micro-pulsations}

Through induction magnetometers, Kato et al. (1959) observed geomagnetic pulsations with large periods (from 70 to $100 \mathrm{~s}$ ) accompanying Sfe in large flares. They suggested that hydro-magnetic oscillations excited by an increase in radiation in the outermost layers of the atmosphere could be a possible cause. Pinter (1968) observed the simultaneity of the beginning of the pulsations with the Sfe coinciding with the impulsive phase of the development of $X$-radiation. Kuwashima \& Uwai
(1985) found a correlation between the Sfe growth ratio and its effectiveness in pulsation excitation.

\subsection{Night Sfe}

The first evidence of the possibility of Sfe occurring in the dark hemisphere was presented by Ohshio (1964). This author noted that the amplitude of nocturnal Sfe was small (between $1 / 10$ and $1 / 20$ of those recorded near the subsolar point) and that the shape at the maximum was not very different from that presented by Sfe in the lit part of the world. He also found that the effects of an Sfe were detectable in the polar zone. He interpreted that these geomagnetic effects of solar flares were due to induction currents that were forced to flow into the dark part of the Earth's ionosphere due to sudden increases in the conductivity of the illuminated hemisphere. Later, other observations by Pintér (1969) and Srivastava \& Abbas (1975) also confirmed this idea.

Using data between 1969 and 1971 from the equatorial station at Kodaikanal and also from Huancayo and Kakioka, Sastri \& Murthy (1975c) and Sastri (1975a, 1975b) found amplitudes greater than those found by Ohshio (1964). They also reported rise and fall times of the nocturnal Sfe as being greater than those of the daytime events. The delay time between the maximum X-ray flux and the maximum of the nocturnal Sfe ranged between 1 and $52 \mathrm{~min}$, also greater than times predicted by Ohshio's calculations. These same authors (Sastri \& Murthy, 1975b) found another indication of the existence of night Sfe when analysing the event of October 15, 1967, when an X-ray flare was recorded simultaneously with the Sco X-1 satellite (in the lit part) and with a balloon (in the dark part). Villante \& Regi (2008) studied the Sfe occurrence of a case in the dayside geomagnetic field, and at the same time they identified explicit signatures of the event at several stations which were also in the dark sector.

The subject is of great complexity and interest. It is a subject still open and awaiting further morphological studies. This will require careful selection of events and the use of a greater number of stations than in previous studies, in both night and day sectors.

\section{Morphology of Sfe}

\subsection{General characteristics}

In a schematic way, we can say that the main characteristics of Sfe can be summarised as: (1) morphology: a crochet shape (Fig. 1); (2) vision: simultaneously in the Earth's sunlit hemisphere; (3) beginning: simultaneous to the flare observation; (4) duration: a few minutes (Fig. 2); (5) amplitude: a few nanoTeslas.

In fact, the main characteristics of the Sfe were found through statistical studies by Grafe (1958), Nagata (1952), and Pinter (1967). At the Ebro Observatory, research on the geomagnetic effects of chromospheric flares began with the work of Princep (1947). He confirmed that the flare frequency curve approximately follows the solar cycle curve given by Wolf's numbers, with the most likely ones being those of importance 1 (Sect. 4.2). Those of importance 3 occurred almost exclusively in active years. 

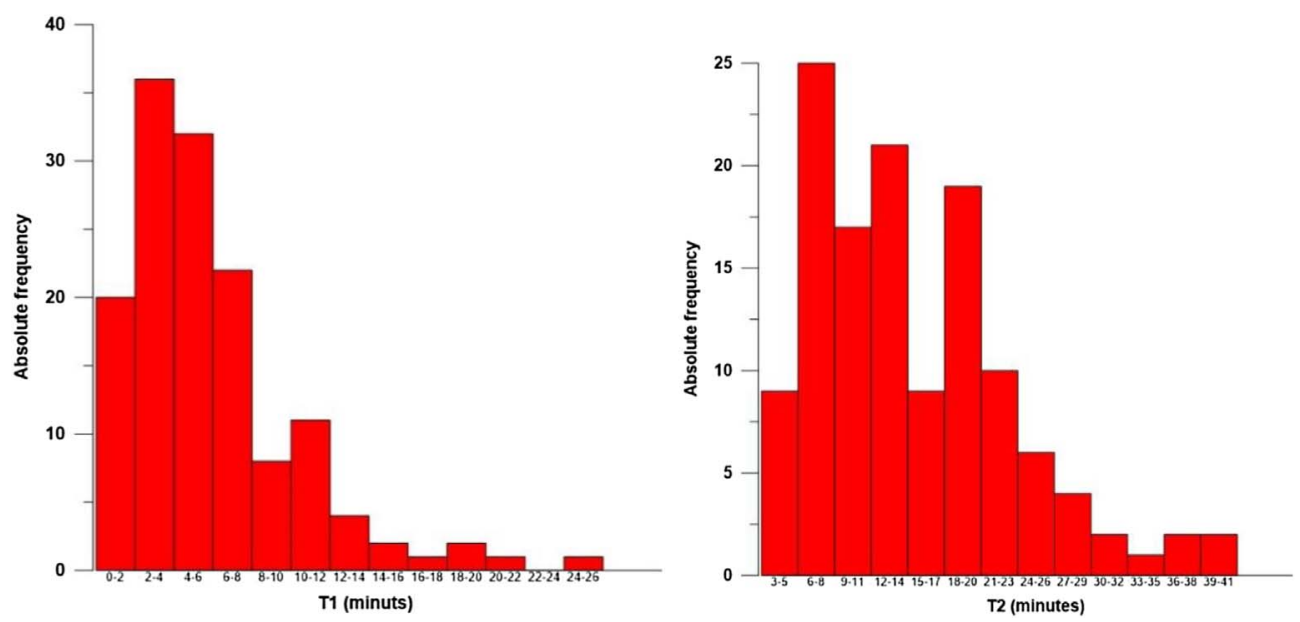

Fig. 2. Distribution of the rise time, $\mathrm{T} 1$ (the time from the commencement to the maximum) on the left, and the decay time, T2 (the time from the maximum to the end) on the right from Sfe data obtained during the period 1953 to 1985 at Ebro Observatory.

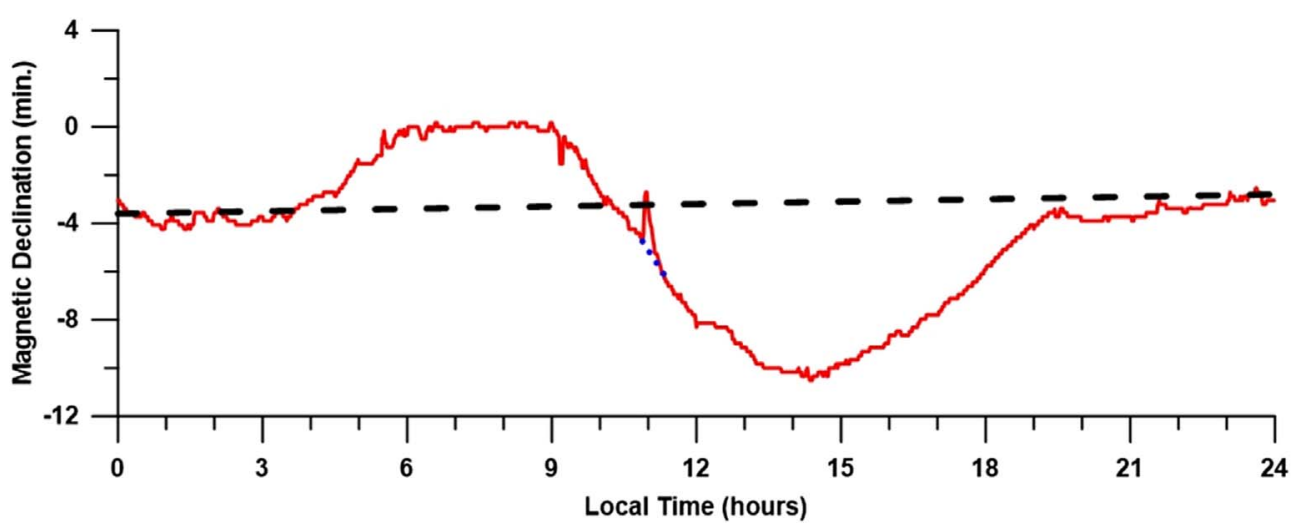

Fig. 3. Reversed Sfe recorded at Ebro Observatory at 11-07-1978. D component is represented by a solid red line, zero line (nocturnal level) by a black dashed line, and the regular variation (interpolated) during the Sfe by a blue dotted line. At the moment of the Sfe (10:56) Sq variation presented negative values (Sq focus was on the West) while Sfe presented positive values (Sfe focus was on the East).

In an unpublished work, Bolufer and Cardús (priv. commun.) presented at the XX IAGA Assembly in Helsinki the daily and annual variation of the intensity and direction of the Sfe observed at Ebro Observatory during the period 1949-1957. They found a main maximum of occurrence near noon $(12-13 \mathrm{~h})$ and another secondary one in the morning (8-9 h). They observed a hibernal minimum and an equinoctial maximum which was not very well-defined. In the declination component, the passage from East to West occurred approximately $1 \mathrm{~h}$ later in the Sfe than in the Sq. These results were similar to those obtained for Abinger Observatory (Newton, 1946), Lerwick and Eskdalemuir (McIntosh, 1951) and Lövo (Eleman, 1961). The phase difference between the vectors Sfe and $\mathrm{Sq}$ had a maximum between $10^{\circ}$ and $11^{\circ}$ with an angle value of about $13^{\circ}$ and a minimum between 15 and $17 \mathrm{~h}$ with an angle of only $12^{\circ}$.

Using a longer series of Sfe events recorded at Ebro Observatory, Curto et al. (1994a) performed a statistical analysis to determine the main morphological characteristics. Sfe at Ebro have a mean duration of $16 \mathrm{~min}$ and a mean rise time of $4 \mathrm{~min}$ and a mean decay time of $12 \mathrm{~min}$. The mean amplitude of Sfe is
$14 \mathrm{nT}$. It represents about $30 \%$ of the amplitude of the diurnal variation at Sfe time, and is in good agreement with former works.

\subsection{Reversed Sfe}

Although Sfe are mostly believed to be an effect of a simple increase of the $\mathrm{Sq}$ currents, in some cases they produce magnetic variations in the contrary sense of Sq (Fig. 3). These puzzling situations have been called reversed Sfe. Reversed Sfe are not a rare or sporadic phenomenon at Ebro; in fact, they occur quite frequently (compared to the appearance of Sfe). Bolufer and Cardús (priv. commun.) determined a diurnal variation in the number of reversed Sfe phenomena, and found a clear maximum between 10 and $11 \mathrm{~h}$. This contrasted with the fact that the number of reversed Sfe in Abinger and Lerwick-Eskdalemuir was very low, and there were none at Huancayo. They also found that reversed Sfe occur more often during equinoctial months and the correlation with solar activity is weaker than that found for regular Sfe. Curto et al. (1994a, 1994b) modelled the Sfe currents and obtained a convincing 
explanation for the genesis of these phenomena: the large phase shift of the magnetic vector observed before noon, resulting from a descent of the "centre of gravity" of the conducting mass that, combined with a very different regime of neutral winds in the lower and in the middle parts of the dynamo region, produce a change in the direction of the integrated currents.

\section{Service of rapid magnetic variations}

\subsection{History of the service}

The International Association of Geomagnetism and Aeronomy, IAGA, belonging to the International Union of Geodesy and Geophysics, IUGG, can in fact be considered the highest organ of Geophysics worldwide. Among its competencies, it is responsible for the study of the Earth's magnetic field and its variations. In order to characterise the short-term variations that the geomagnetic field undergoes, the Service of Rapid Magnetic Variations (SRMV) was created at the Assembly of Rome in 1954, initially framed under Committee No. 10. The leadership of this Service has been entrusted to the Ebro Observatory since its creation (Curto et al., 2007) with Father A. Romañá, director of the Ebro Observatory, assumed the first presidency. At the Copenhagen Symposium (1957), a definition for Sfe and the study of reversed Sfe were proposed. At the Utrech Symposium (1959), a provisional atlas was delivered (IAGA, 1959). Here, Veldkamp presented his work on Sfe currents. Collaborating observatories (whose number had grown to 92 by then) were requested to indicate the means used for their selection of Sfe.

At St. Gall Assembly (1967) it was specified that Commission IV should promote the study of transient magnetic variations (Sfe, SSC, bays, and pulsations) as well as regular recurring variations $(\mathrm{Sq}, \mathrm{L})$ and should develop knowledge regarding their origins. The group concerned with Rapid variation morphology was consolidated as part of the permanent International Service of Geomagnetic Indices with the capacity to collect the necessary data and calculate and publish the indexes and records of outstanding rapid variation events. Within Commission IV, this body became part of the working group n1-1 "Morphology and indexes" whose objective was to obtain an image of the distribution in time and space of rapid variations and their characteristics. Regarding the Sfe, the difficulty of their observation was noted again due to the lack of their own characteristic shape. The use of two qualifiers in the "checking-lists" (lists of events already qualified by the observatories) was proposed to increase the accuracy of the information on the phenomenon.

At the Madrid Assembly (1969), the work of Van Sabben was commented on again and the results of the statistics regarding the interest of the publication of the Sfe (among other phenomena) in the IAGA newsletters within the scientific community were given. Information on the SSC and Sfe was the most appreciated. At the Assembly of Grenoble (1975), in resolutions 5 and 6 , the importance of the lists of rapid variations established by the Ebro Observatory and published in the IAGA series of bulletins was recognized and it was recommended that this observatory continue with this work, especially in relation to the SSC and Sfe phenomena.
At the Edinburgh Assembly (1981), Father Cardús who had taken over the responsibility of the SRMV in 1980, pointed out an alarming scarcity of observatories reporting Sfe and their poor geographical distribution. This fact resulted, on the one hand, in difficulties in discerning the reality of the event and, on the other hand, in not detecting many Sfe. He also pointed out in successive Assemblies the difficulty of determining Sfe, due to the lack of a clear definition of their morphology. He also explained that some observatories reported consistently very clear Sfe during their local night, contrary to what would be theoretically expected.

Father Alberca succeeded Father Cardús in 2000 as chairperson of the Service of Rapid Magnetic Variations and J.J. Curto took over this responsibility in 2018. By taking advantage of the new facilities in data access provided by the INTERMAGNET network, a modification was introduced into the procedure of data treatment. The "checking lists" were no longer used for determining Sfe. As a first step, the events taking place at times when no solar flare had been reported at all were rejected from the lists sent by the reporting observatories. The remaining data were confirmed with a study of the registers of INTERMAGNET network accessible to the Ebro Observatory. The SRMV carried out the classification of the phenomenon with the traditional letters and numbers formerly provided by the reporting observatories. In this way, the discerning criterion was more uniform. To determine the region where the phenomenon was observable, global maps showing the light and dark zones were constructed. Finally, with all this data, the event was classified.

At the Vienna (1991), Upsala (1997), and Montreal (2019) Assemblies, it was recommended once again that the lists of rapid variations and in particular those of the Sfe be continued, given their usefulness as a reference for many geophysical works. It is worth noting that during its almost 90 years of existence, in addition to its regular daily activities of providing reliable lists of events and updating normatives with regards to the current state-of-art, the SRMV has aimed to focus the interest of the scientific community on this field and to promote the study of the physics of these variations. Advances in the physical understanding of the rapid variations, including Sfe, have enabled improvements to the definitions, the determination methods used, and the quality of the data sets produced.

\subsection{IAGA bulletins}

The bulletins published annually by the IAGA refer to the global magnetic activity indices as well as the rapid variations of the magnetic field in particular Sfe (IAGA, 1954-1990).

The procedure to draw up the Sfe lists is as follows: using the reports that a network of observatories distributed throughout the world send monthly to the Service of Rapid Magnetic Variations regarding any movement suspected of being an Sfe and, where appropriate, its ionospheric, solar or radioelectric confirmation, a list of selected events is prepared where those events that coincide with other clearly established magnetic phenomena are removed from the list, as well as those events that, having no other confirmation, are reported by only one observatory without the other observatories in their neighbourhood recording any movement. Until 2000, these master lists (checking lists) were forwarded to the collaborating centres to 
Table 1. Codes used to qualify the type of movement in the magnetogram.

\begin{tabular}{lccccc}
\hline Code & A & B & C & D & E \\
\hline Movement & Very clear & Clear, normal & Very weak & $\begin{array}{l}\text { Not observed, although registration } \\
\text { is satisfactory (calm) }\end{array}$ & $\begin{array}{l}\text { Great magnetic } \\
\text { stirring (disturbed) }\end{array}$ \\
\hline
\end{tabular}

Table 2. Opinion of the observer regarding the likelihood of this movement being an Sfe.

\begin{tabular}{lcccc}
\hline Code & 0 & 1 & 2 & 3 \\
\hline Appreciation & Nonexistent & Unlikely & Likely & True Sfe \\
\hline
\end{tabular}

confirm and qualify the events. The observatories responded in a concerted manner according to a fixed scheme. They used an index letter that refers to the existence of the movement (Table 1).

A complementary number referring to the opinion of the observer regarding what the type of movement might have been was also given (Table 2).

Based on all these observatory data, a world map was made of the zonal distribution of these observations of the magnetic traces of the phenomenon. In addition, a synoptic study of the ionospheric (SID), solar $\mathrm{H} \alpha$, and radioelectric (microwave) data was made. With all this information, a final qualification of the phenomenon was made, with the possibility that they may be (a) true, (b) doubtful, or (c) rejected. Finally, the definitive lists of certain and doubtful Sfe were put in order of time. For each event, the start time (average value) and the observatories (with their three-letter IAGA code) were given together with the qualification of the event. The observatories that answer differently from $\mathrm{D}$ and were in the night zone at the time of the Sfe were given in parentheses; if they were in the twilight zone, this was indicated with dotted parentheses. These agreements, however, changed over time. An Sfe was considered doubtful when most well-located stations (with respect to the subsolar point) did not report any movement or when almost all the stations around the world reported a clear movement. This also applies when all data were masked by a planetary scale disturbance or when the solar, radioelectric, and ionospheric registers did not show any clear effect that could be associated with an Sfe. Nowadays, the method has been simplified and a second round of forwarding the checking lists to the observatories is no longer carried out. It is difficult to remove subjectivity entirely from the process and some uncertainty in the results is inevitable.

\section{Detection of Sfe}

\subsection{The origin of the Sfe lists}

Several rapid magnetic variations attracted the attention of scientists from an early moment. As mentioned previously, at the IAGA General Assembly (Rome, 1954) a new committee was created on rapid variations and Earth currents with A. Romañá from the Ebro Observatory elected as chairperson. The task of the committee was to create lists of events, including sudden storm commencements (SSC), pulsations during sudden commencements (PSC), sudden impulses (SI), and solar flare effects (Sfe), which were to be published in the IAGA annual bulletins (Curto et al., 2007). Since then, the working procedure for detecting Sfe events has been more or less the same and is still based on manual methods. These consist of visual identification on the observatory magnetograms using the observers' experience of previous events for each observatory's location. The recently successful automatic detection of SSC was probably due to the fact that they mostly have a common morphological pattern: the main signal, a sudden increase in the $H$-component, is similar around the world. However, this is not true for Sfe. They are elusive, so previous attempts at an automatic detection of Sfe failed and until now there have been few references in scientific literature regarding this possibility.

\subsection{Difficulties in Sfe detection}

The first and most obvious difficulty in Sfe detection is that they do not have a definite morphological pattern. The Provisional Atlas of Rapid Variations (Romañá, 1959), which explains the first attempts at a systematic overview of the morphology of Sfe, states: "It is almost impossible to give comprehensive examples of Sfe, their aspect changing considerably with circumstances (magnetic or telluric component, moment of the diurnal variation, sun's altitude, intensity, etc.)". As a comment on some presented examples, it concludes: "But the following examples, taken also from cases confirmed by direct observation of the solar flare, have an aspect rather confusing". No one looking at only one single magnetogram can conclude whether a movement is or is not, in fact, an Sfe because this is only a partial view of the whole process (Curto \& Gaya-Piqué, 2009a, 2009b). Sfe can appear only in the $X$-magnetic component, only in the $Y$-magnetic component, in both components, or in neither of them. Their shapes are irregular and unpredictable. Sometimes they are like a crochet, and on other occasions they look more like a "V-valley" shape. Sometimes they are steep, and at other times they are smooth. According to Curto et al. (2016b), this is due to the temporal variations in the radiation, which have irregular shapes in their origin: the solar disturbances. Moreover, Sfe events are the result of the action of several radiation bands (X and UV) that occur at different heights of the sun, so they could be synchronic or not. They also have different relaxation times (Richmond \& Venkateswaran, 1971). Thus, to achieve a certain degree of certainty in the Service of Rapid Magnetic Variations (Curto et al., 2007), other contemporary ionospheric effects are usually sought out (Tsurutani et al., 2009). To this end, García-Rigo et al. (2007) developed a solar flare detector using the Global Positioning System (GPS) capabilities to monitor the ionospheric total electron content (TEC). This detector is able to automatically identify sudden changes of the ionospheric ionization. Also, Meza et al. (2009), analysing an Sfe case, considered the quantitative and qualitative relations between a solar flare 
and the ionospheric and geomagnetic variations that it produces. The ionospheric effect of the solar flare effect was analysed from the variation in the vertical total electron content (vTEC) data obtained from GPS. They concluded that for Sfe detection, the distance between the subsolar point and each observatory is not the only parameter to be considered in detection; for an Sfe, the intensity and position of the currents overhead should also be considered. The maximum geomagnetic variation is always simultaneous to or a little later than the maximum intensity of the X-ray and the maximum vTEC is generally later than both of them.

On the other hand, Selvakumaran et al. (2015) also studied the relationship between the solar-flare-induced D-region ionospheric and geomagnetic perturbations through the change in the VLF amplitude. During the flare time, electron density estimated by using the D-region reference height $\left(H^{\prime}\right)$ and sharpness factor $(\beta)$ for each class of solar flare shows a maximum increase in the order of 80 times as compared to the normal day values. Electron density was found to increase exponentially with increases in the solar flux intensity. At the equatorial station of Tirunelveli, they found a maximum increase in the horizontal component of the Earth's magnetic field of $8.5 \%$ for M-class solar flares. Finally, Curto et al. (2018) analysed the impact of X9 flares on the magnetic field but also on the ionosphere as registered on the vertical incidence ionospheric sounder located at Ebro Observatory. They put the emphasis on the use of this instrument to detect solar flares by means of the absorption observed in its ionograms.

Curto \& Gaya-Piqué (2009b) carried out an in-depth analysis of some limiting factors in the detection process. One of these factors is the natural noise caused by disturbances in the geomagnetic field masking Sfe variations, especially those of small amplitude. Another factor limiting the efficiency in the detection is the irregular distribution of the magnetic observatories. Due to the reduced area of manifestation of Sfe, the method used to detect them is highly dependent on the availability of multiple observation points. Some areas like North America, despite good observatory coverage, appear as "blind" zones since observatories do not carry out the required work for Sfe detection. Others areas, such as most oceans and some parts of the southern hemisphere, have very scarce observatory coverage.

A detailed attempt to provide a means of confirming Sfe was made by Curto et al. (2019). They constructed a Solar flare monitor based on GNSS and trimmed it to confirm the presence of ionospheric ionization which is able to produce solar flare effects (Sfe) in geomagnetism. They analysed a period of 11 years (2008-2018) and imposed some conditions to adjust the GNSS-SF detector so as to produce a list of candidates that match the Sfe lists provided by the SRMV. Optimal values of the threshold to minimize false positive rates and to maximise the true positive rates were found. Also, the number of candidates to be revised played an important role in their decision. Finally, these authors revised the limitations of both methods. Background noise, suddenness, temporal and spatial blind windows, or spectral unbalance conditioned the detection. They found that suddenness in the variation is a key factor for detection.

\subsection{Automatic detection}

Regarding their detection using an automated procedure, Sfe have been very elusive. As mentioned above, their small amplitude, close to the level of noise produced by other natural phenomena, and their highly variable irregular shapes make it extremely difficult to apply pre-designed patterns. Automated Sfe detection is a topic that remains relevant today and, if successful, would be a valuable tool for the observatory community. Curto et al. (2017), taking advantage of the special characteristics of Sfe, including their spherical symmetry around the vortex and different time durations between Sfe and other natural variations with similar spatial distributions like Sq, were able to separate the Sfe signal from other natural disturbances. They defined an Sfe index by taking into account the derivative of the radial contribution of the Sfe disturbances with respect to the vortex of the current system responsible for the Sfe variation. Finally, using this they have constructed an Sfe detector, which is now in a test phase.

\section{Progress of Sfe study}

\subsection{Geo-effectiveness}

\subsubsection{Past studies}

Regarding the production of geomagnetic crochets, Princep (1947) found that their probability of occurrence depended on the importance of the flare and its position on the solar disk, as well as on the height of the sun over the horizon. It also depended on the instantaneous phase of the diurnal variation, which conditioned the appearance of the geomagnetic crochet. However, the data coverage was limited. Cardús (1952) resumed the study using data collected between 1949 and 1951 from many observatories around the world. Cardús found the heliographic position of solar flares bore no influence on the effectiveness of the production of Sfe. Cid (1960) extended the same study to use data from the years 1949 to 1956 and confirmed Cardus' results.

Using Lovö data, Eleman (1961) verified that only a small number of solar flares had an appreciable effect on the magnetograms. This was attributed to the magnetic noise almost always present at high latitudes. He pointed out the necessity to analyse the spectral radiation of the flares to understand their efficiency. Finally, he found an East to West asymmetry in the flares producing Sfe in agreement with what Grafe (1958) had observed in Potsdam-Niemegk.

\subsubsection{Recent studies}

Curto \& Gaya-Piqué (2009a) studied the influence that the spectral nature and solar flares' position on the solar disk have on the production of Sfe. They found that the probability of a flare producing Sfe depends on the spectral band in which we observe it, and is higher when the flare is important both in $\mathrm{H} \alpha$ and X-ray emissions. In any case, X-ray flares are better markers than $\mathrm{H} \alpha$ flares for producing $\mathrm{Sfe} . \mathrm{H} \alpha$ and X-ray emissions were considered in many different divisions of the solar surface and their effectiveness on Sfe production were compared. They found that no region is more favored than another on the solar disk for Sfe production. Hence, the results Princep (1947) obtained could be down to the small dataset the author had to work with. Curto \& Gaya-Piqué (2009a) produced their 
statistics from a much larger dataset, with more than 30 years of data.

Furthermore, Van Zele \& Meza (2011) undertook the task of evaluating the efficiency of geomagnetic solar flare effects in X-ray solar flare detection. They concluded that the identification of solar flares using Sfe is affected by: the intensity and average growth rate of solar flare radiation - the quicker it is, the more easily the solar flare is detected as Sfe; the position of the geomagnetic observatory, as observatories placed in the summer hemisphere identify the solar flare more easily, so the uneven geographical distribution of observatories makes solar flare identification difficult; the existing geomagnetic perturbation previous to a solar flare; and the likeness between the Sfe and other geomagnetic variations. A more uniform spatial distribution of observatories would improve the identification of solar flares as well as the simultaneous use of other magnetic and ionospheric confirming parameters.

\subsection{Physical models}

\subsubsection{Past studies}

In 1957, Pratap solved the ionospheric dynamo equation for a conductivity produced by solar-flare ultraviolet radiation from the sun. He computed the amplitude of the geomagnetic horizontal component of the crochet and compared it with observations in Abinger and Alibag. Later, other attempts to model Sfe used theoretical parameters instead, due to the lack of direct observations. Ohshio (1964), with a model of solar radiation with X-rays at wavelengths between 1 and $20 \AA$ as the main ionizing agent, calculated the height distribution of the electronic density and obtained, worldwide, a reasonable explanation of the magnetic effects of the flare. Later, Richmond \& Venkateswaran (1971) analysed several Sfe events with a composed structure model of two spatial and temporally separated magnetic field potentials. They associated a "fast" component related to EUV radiation (100-1000 $\AA$ ) and another "slow" component related to soft X-rays (1-100 $⿱$ A).They also tested a simulation of these currents with a simple model of radiation, ionization, and neutral wind. However, this model could not explain the asymmetries observed in the contours of the current systems.

\subsubsection{Recent studies}

Curto et al. (1994a) modelled the occurrence of reversed Sfe (with respect to $\mathrm{Sq}$ ) with a parametric model they constructed. With this model, reversed Sfe are seen to be a physical consequence of the ionospheric current system geometry and are due to the displacement that the Sfe system undergoes in longitude and/or latitude with respect to the Sq system. Reversed Sfe must appear in zones between the focus of both vortices. The geometric space for phase differences greater than $90^{\circ}$ is another ellipse whose major axis is aligned with the segment that links both vortices. According to their model, which is essentially valid for the central hours of the day, only a few observatories placed inside a narrow band of mid-latitudes and only at certain hours and seasons of the year, will be able to record reversed Sfe. Most observatories will be outside this strip, so that the phase differences between the $\mathrm{Sfe}$ and $\mathrm{Sq}$ vectors at these sites will be too small for reversed Sfe. Hence, it also becomes clear why reversed Sfe phenomena are less commonly seen. It is the unique location of Ebro, in relation to the $\mathrm{Sq}$ foci, which enables this investigation to be carried out.

Following the above, Curto et al. (1994b) undertook a more complex task: to construct a model for Sfe phenomena combining several semi-empirical models derived from satellite and radar data obtained during the previous two decades. They used Heroux et al. (1974) for regular and Donnelly (1976) for flare flux radiation, Ohshio et al. (1966) for optical depth, Hedin (1987) for neutral composition and Oliver (1975) for ion composition, Dymek (1989) for ion production rates, Stubbe (1968) for collision frequencies, Bernard (1978) for neutral winds, Blanc \& Amayenc (1979) for the electric fields and Mazaudier \& Blanc (1982) for electric currents. This unidimensional physical model allowed them to reproduce the main characteristics of the Sfe at the Ebro Observatory and quantify the phase difference between the Sfe and Sq vectors. In particular, it explained the large phase shift of the magnetic vector observed before noon, resulting from a descent of the "centre of gravity" of the conducting mass that combined with a very different regime of neutral winds in the lower and middle parts of the dynamo region, produce a change in the direction of the integrated currents. This physical integrated model allowed them to give an explanation of the reversed Sfe occurrence.

Curto et al. (2006) checked the physical model for Sfe by modelling the opposite situation: the temporary cutoff of the ionizing solar radiations during an eclipse. Previously, they had evaluated the radiative profile of the photosphere and corona layers for frequencies of radiation responsible for ionizing the Earth's upper atmosphere and then constructed a model to determine the flux distribution for places in the shadow path at any time of the event. Afterwards, they applied it to a model based on the equivalent electric current schema to predict its magnetic effect on Earth.

Even with the strong simplifications used, the model managed to reproduce the real magnetic disturbances produced by the solar eclipse.

\subsection{Temporal evolution of the electric currents producing Sfe}

\subsubsection{Past studies}

Tracing the temporal evolution of the currents producing Sfe had already been attempted by some authors (Veldkamp \& Van Sabben, 1960; Van Sabben, 1961). With a limited number of observatories, they only achieved quantitative descriptions of the current systems responsible for the Sfe disturbances. Later, Curto et al. (1994a), using data from 67 observatories, performed a global study of an Sfe event, which was observed at Ebro as a reversed Sfe. In this case, in the Northern Hemisphere the Sfe equivalent current system was about $1 \mathrm{~h}$ local time eastward of the Sq system and it formed $4^{\circ}$ higher in latitude. However, the method used for drawing the path of the currents was rather simple and followed the classical method of Chapman \& Bartels (1940).

\subsubsection{Recent studies}

A more sophisticated attempt was carried out by Gaya-Piqué et al. (2008). They analysed the prompt Sfe associated with a 


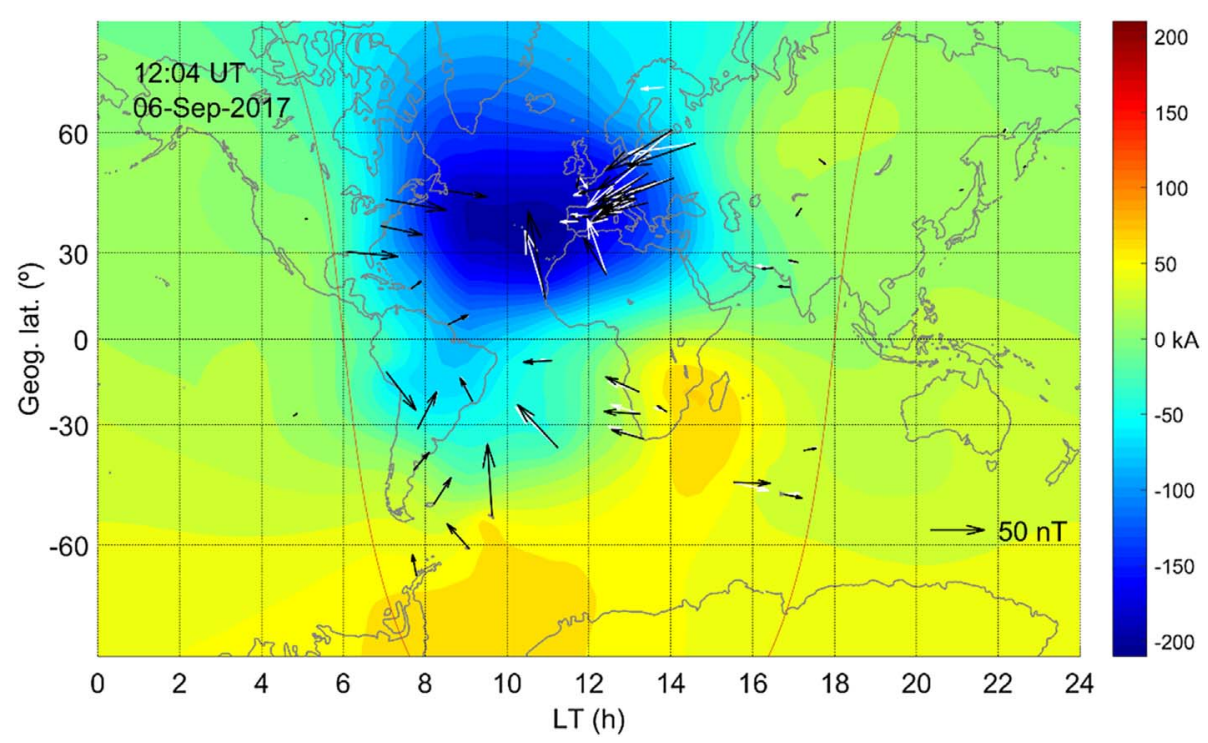

Fig. 4. SECS-derived equivalent current system flowing at ionospheric heights at 12:04 06-Sep-2017. Black arrows represent the measured Sfe field, while white arrows show the modelled Sfe field using the SECS technique. The dotted red line represents the terminator.

strong X-ray flare that occurred on December 5, 2006, by using a spherical cap harmonic analysis (SCHA) on a network of European magnetic observatories. They modelled the ionospheric equivalent current system responsible for the Sfe, as well as for the regular diurnal variation Sq on that day allowing simultaneous space and time interpretation. They found that the Sfe equivalent current whorl was distinct from that of the Sq; its size was much smaller, it appeared to the north (between $3^{\circ}$ and $10^{\circ}$ ), and around forty minutes earlier in local time with respect to that of the Sq. This confirmed previous results found by authors for different Sfe (Van Sabben, 1961; Curto et al., 1994a). There are some limitations to the use of this method, however, such as the difficulty to discriminate between internal-external sources and the need for a careful selection of the size of the cap to get coherent results. The authors had to perform different tests, such as modifying the adopted temporal basis functions or the maximum spatial and temporal expansion degrees, all of which resulted in a somewhat cumbersome procedure. It would therefore be impractical for processing large data sets that would be necessary, for example, in the automatic detection of Sfe events.

Using the Spherical Elementary Current Systems method, Curto et al. (2018) were able to model the whole episode of Sfe corresponding to a X9 flare (Fig. 4). They analysed the impacts of this flare on the Earth's magnetic field and the temporal evolution of this event, tracing the current system evolution during the Sfe lifetime in detail. As expected from other previous works, e.g. Richmond \& Venkateswaran (1971), a sharp increase in current intensities occurred at the beginning. The peak of the disturbance was reached after a few minutes, when hard X-rays were dominant, while a slow decay followed the advent of soft X-rays and EUV rays. The modelled current systems appeared abnormally displaced in longitude with respect to the subsolar point. The northern vortex showed up about $2 \mathrm{~h}$ in advance of the subsolar point meridian, while the southern vortex was about $3 \mathrm{~h}$ behind it. Both remained static, showing no significant shift over the whole episode. Although this event occurred during the equinox, a clear prevalence of the northern hemisphere was observed.

Annadurai et al. (2018), using a spherical harmonic analysis of two geomagnetic crochets near the magnetic equator, found a very different response in the ionospheric currents between these two events. The equivalent current system of the geomagnetic crochets for the September 24, 2011, event showed a similar pattern with the background $\mathrm{Sq}$ current system while the crochet current system for the August 9, 2011, event revealed a different pattern from the background $\mathrm{Sq}$ current system in both northern and southern hemispheres. Annadurai et al. concluded that this unusual geomagnetic crochet event was dominated by the ionospheric currents at D-region altitudes, unlike that of the E-region Sq current system.

\subsection{Dynamic aspects}

In their worldwide analysis of the 2003 Halloween episode, Villante \& Regi (2008) corroborate that Sfe characteristics were basically controlled by the zenith angle of the observing stations. The Sfe onset and initial phase reveal a close correspondence with those of the EUV flux while, at higher latitudes, the geomagnetic traces show some correspondence with the behavior of the X-ray flux. The relationship suggests a deeper penetration of the X-ray flux. In any case, it was seen that Sfe were not a mere increase of the pre-flare current system.

Curto et al. (2016b) analysed the temporal response of the Earth's magnetic field to sudden large energy releases by studying the driver mechanisms involved in the decay of Sfe. The decay time is strongly dependent on the balance in X- and UV-ray contributions. Only the most energetic period of the $\mathrm{X}$-ray enhancement is actively producing Sfe. They identified the time constant as an important factor for detection because it restricts the detected events to those having a sharp shape with an abrupt change of slope. 


\section{Revisiting large historical flares}

Large flares soon attracted the attention of researchers. Eleman (1961) analysed the two giant flares of July 3, 1957, and March 23, 1958, and the magnetic crochets produced by them. Recently, the interest in extreme Space Weather events has been increasing for both practical and theoretical reasons (Gopalswamy et al., 2005). Using indirect measures of ionospheric disturbances some authors sized big solar flares when direct measures were not available due to the non-existence of data or a saturation of the detector. Thomson et al. (2004, 2005 ) were the first to estimate the X-ray peak time and magnitude of the 4 Nov 2003 flare using the ionospheric disturbance. They concluded that the flare peaked between 19:45 and 19:46 UT, and that its magnitude was X45 \pm 5 . Brodrick (2005) used observations of attenuation of the galactic radio background from $20.1 \mathrm{MHz}$ riometers to estimate the X-ray magnitude of the same solar flare. The best fit gave a peak flux of $4.0 \mathrm{~mW} / \mathrm{m}^{2}$ (X40), peaking at 19:46 UT. Kiplinger \& García (2004) investigated the flares of AR486 Oct-Nov 2003, referring to those other flares with similar time profiles from the same active region to estimate the peak magnitude of this flare.

The August 28-September 7, 1859, episode, known as the Carrington event, is undoubtedly an obligatory reference in any Space Weather summary (Carrington, 1860; Stewart, 1861; Cliver \& Svalgaard, 2004; Boteler, 2006). The Carrington flare emitted such a large quantity of radiation in the visible range that it became the first flare ever reported and the first to be linked to a terrestrial response (Carrington, 1860; Stewart, 1861). This led to the re-examination of various aspects of the Carrington event, especially the flare size. Thus, in Boteler (2006), the Carrington flare magnitude was inferred to be of similar magnitude to the 4 November 2003 one since the Sfe recorded at Victoria was $100 \mathrm{nT}$ and Victoria was of a similar geomagnetic latitude to London and the local times of the two flares were similar. Clarke et al. (2010) were the first to attempt to establish an empirical relationship between the variation peak of Sfe (magnetic field) and the maximum radiation (X-ray flux). They used more than 300 observations of Sfe. From the relationship established, they estimated the Carrington flare magnitude as $\sim \mathrm{X} 42$ (based on Greenwich Sfe) and $\sim$ X48 (based on Kew Sfe). Then, Cliver \& Dietrich (2013) adopted a combined estimate from Boteler (2006) and Clarke et al. (2010), of X45 $( \pm 5)$ as the classification that they carried forward within their own study, which was about various physical limits for extreme events/storms. Most of these studies agree that the Carrington flare may have been a very large solar flare.

On the other hand, as previously mentioned, the radiation during the large solar flare of 4 November 2003 saturated the X-ray radiometer. Hence, Curto et al. (2016a) used an alternative approach to try and determine these values (Fig. 5).They estimated the values from the perturbations they produced in the Earth's Sfe. Firstly, and similar to Clarke et al. (2010), they established an empirical relationship between the variation in the radiation (cause) and its effect on the magnetism (consequence). Then, using the inverse function, they estimated the energy flux of both events, the 4 November 2003 flare and the 1 September 1859 flare. They found that both flares can actually be classified as being a little larger than the previously reported X45.

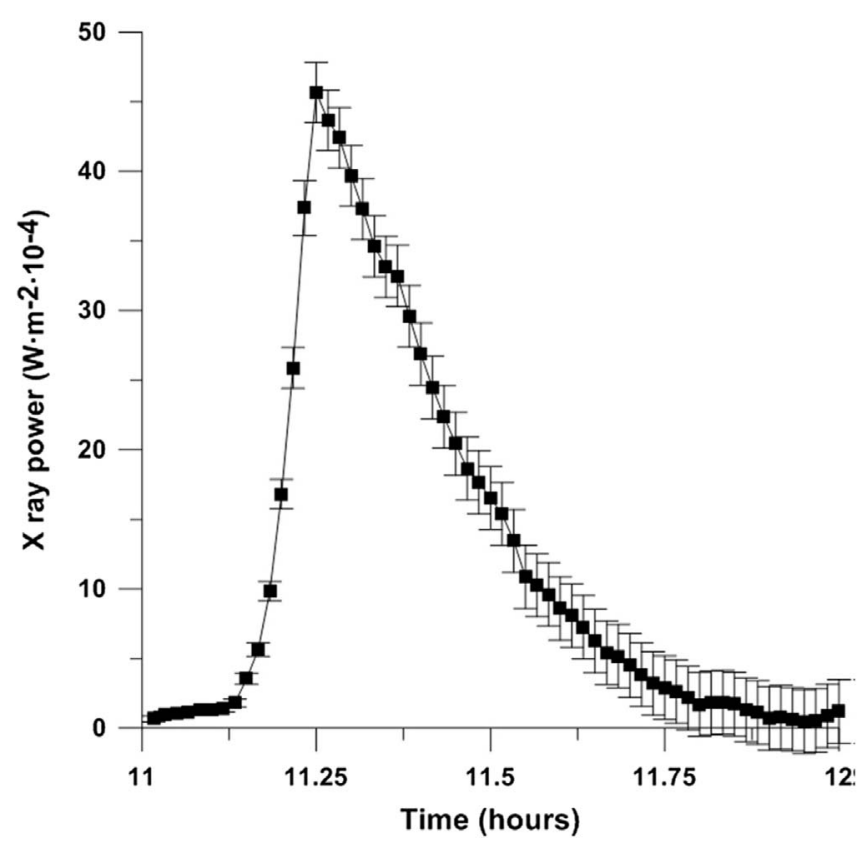

Fig. 5. X-ray flux of Carrington event on 1 September 1858 modelled using a mathematical method, with a maximum of $\mathrm{X} 45.7 \pm 2.2$ at 11:15 (from Curto et al., 2016a).

Recent papers looking at several other parameters (Barnard et al., 2011; Ruzmaikin et al., 2011), including observed CME speeds and the strength of the equatorial current system in the Earth's magnetosphere, concluded that the risk of an extreme space weather episode could be as high as $12 \%$ in a decade (Riley, 2012). From this result, the UK Royal Academy of Engineering issued a report on extreme space weather in 2013 (Cannon, 2013). They deduced a return period or recurrence interval of 79 years for a super-storm. On the other hand, Thomson et al. (2011) quantified the probability of having extreme behavior in geomagnetic activity as ranging from 100 to 200 years. Curto et al. (2016a) also computed the return period for a Carrington-like flare. Assuming that this event had X45 intensity they estimated the return period to be 90 years. Thus, different approaches converge to lead to the conclusion that extreme events are very rare and we do not expect one to happen in the near future.

\section{Conclusions}

In this work, we present a comprehensive review of the current status of Sfe research. We started by revising the evolution, principles, and categorisation of the events recorded during solar activity. We described how the progress in our knowledge of geomagnetic flare effects has advanced alongside and together with the advances in Space Weather as they mutually reinforce each other. We discussed several key points in the understanding of Sfe such as their dynamic aspects or their geo-effectiveness. In the last section, we attempted to summarise recent strategies used to estimate big historical events and the probability of them happening again. This is a big 
challenge in a technical society like ours which is so sensitive to these phenomena.

Finally, we can now discuss perspectives and summarise challenges that need to be addressed in future investigations. Specifically, future improvements to models can be expected, as density of data coverage, accuracy, reliability, and the temporal resolution and quality of the data get better. Thus, these improvements will contribute to further progress in the understanding of these phenomena. Furthermore, recent works on automatic detection show promising results and should provide a more exhaustive catalogue of events that could be used as the base of future studies. In this sense, we must emphasise the important role played by the Service of Rapid Variations in promoting the interest of the scientific community in this field and the study of the physics of these variations.

As mentioned before, there are still "boundary" issues as Reversed Sfe or Night Sfe that deserve more studies to find their origin. Hence, we can conclude that, we are not at the final point in Sfe studies yet, but rather at the starting one.

Acknowledgements. The author thanks the referees for their constructive advice which has allowed us to substantially improve the paper. This research was partially funded by the PGC2018-096774-B-I00 (MCIU/AEI/FEDER, UE) project. The editor thanks Ellen Clarke and an anonymous reviewer for their assistance in evaluating this paper.

\section{References}

Annadurai NMN, Hamid NSA, Yamazaki Y, Yoshikawa A. 2018. Investigation of unusual solar flare effect on the global ionospheric current system. J Geophys Res Space Phys 123: 8599-8609. https://doi.org/10.1029/2018JA025601.

Appleton E, Barnett M. 1925. Local reflection of wireless waves from the upper atmosphere. Nature 115: 333-334. https://doi.org/ $10.1038 / 115333 \mathrm{a} 0$.

Barnard L, Lockwood M, Hapgood MA, Owens MJ, Davis CJ, Steinhilber F. 2011. Predicting space climate change. Geophys Res Lett 38: L16103. https://doi.org/10.1029/2011GL048489.

Berkner LV, Wells HW. 1937a. Study of radio fade-outs. Terr Mag Atmos Elec 42: 183-194.

Berkner LV, Wells HW. 1937b. Further studies of radio fade-outs. Terr Mag Atmos Elec 42: 301-309.

Bernard R. 1978. Etude de la variabilité des marées atmosphériques, mesures par radar metéorique et sondeur à diffusion incohérente. Thése de Doctorat d'Etat, Univ. De Paris, Paris.

Blanc M, Amayenc P. 1979. Seasonal variations of theionosphericE $\times$ B drifts above Saint-Santin on quiet days. J Geophys Res 84: 2691-2704.

Boteler DH. 2006. The super storms of August/September 1859 and their effects on the telegraph system. Adv Space Res 38: 159-172. https://doi.org/10.1016/j.asr.2006.01.013.

Breit G, Tuve MA. 1925. A radio method of estimating the height of the conducting layer. Nature 116: 357. https://doi.org/10.1038/ $116357 \mathrm{a} 0$.

Brodrick D. 2005. X-ray magnitude of the 4 November 2003 solar flare inferred from the ionospheric attenuation of the galactic radio background. J Geophys Res 110: A09S36. https://doi.org/10.1029/ 2004JA010960.
Cahill LJ Jr. 1959. Investigation of the equatorial electrojet by rocket magnetometers. J Geophys Res 64: 489-503. https://doi.org/ 10.1029/JZ064i005p00489.

Cannon PS. 2013. Extreme space weather - a report published by the UK Royal Academy of Engineering. Space Weather 11: 138-139. https://doi.org/10.1002/swe.20032.

Cardús JO. 1952. Influencia de la posición heliográfica de las fulguraciones cromosféricas en la producción de corchetes geomagnéticos. Urania 231: 144-168.

Carrington RC. 1860. Description of a singular appearance seen in the sun on September 1, 1859. Month. Notic. Roy. Astron. Soc. 20: $13-15$.

Chapman S, Bartels J. 1940. Geomagnetism. Clarendon Press, Oxford.

Cid E. 1960. Fulguraciones cromosféricas y sus relaciones con los fenómenos magnéticos. Urania 252: 157-172.

Clarke E, Rodger CJ, Clilverd MA, Humphries T, Baillie O, Thomson AWP. 2010. An estimation of the Carrington flare magnitude from solar flare effects (sfe) in the geomagnetic records 2010. In: Royal Astron. Soc. National Astron. Meeting, University of Glasgow, UK, UK.

Cliver EW, Dietrich WF. 2013. The 1859 space weather eventrevisited: Limits of extreme activity. J Space Weather Space Clim 3: A31. https://doi.org/10.1051/swsc/2013053.

Cliver EW, Svalgaard L. 2004. The 1859 solar-terrestrial disturbance and the current limits of extreme space weather activity. Sol Phys 224: 407-422. https://doi.org/10.1007/s11207-005-4980-z.

Curto JJ, Amory-Mazaudier C, Torta JM, Menvielle M. 1994a. Solar flare effects at Ebre: Regular and reversed solar flare effects, statistical analysis (1953 to 1985), a global case study and a model of elliptical ionospheric currents. $J$ Geophys Res 99(A3): 3945-3954. https://doi.org/10.1029/93JA02270.

Curto JJ, Amory-Mazaudier C, Torta JM, Menvielle M. 1994b. Solar flare effects at Ebre: Unidimensional physical, integrated model. J Geophys Res 99(A3): 23289-23296. https://doi.org/10.1029/ 94JA02070.

Curto JJ, Heilig B, Piñol M. 2006. Modeling the geomagnetic effects caused by the solar eclipse of 11 August 1999. J Geophys Res 111: A07312. https://doi.org/10.1029/2005JA011499.

Curto JJ, Cardús JO, Alberca LF, Blanch E. 2007. Milestones of the IAGA International Service of Rapid Magnetic Variations and its contribution to geomagnetic field knowledge. Earth Planets Space 59: 463-471. https://doi.org/10.1186/BF03352708.

Curto JJ, Gaya-Piqué LR. 2009a. Geoeffectiveness of solar flares in magnetic crochet (Sfe) production: I - Dependence on their spectral nature and position on the solar disk. J Atmos Sol-Terr Phys 71: 1695-1704. https://doi.org/10.1016/j.jastp.2008.06.018.

Curto JJ, Gaya-Piqué LR. 2009b. Geoeffectiveness of solar flares in magnetic crochet (Sfe) production: II - Dependence on the detection method. J Atmos Sol-Terr Phys 71: 1705-1710. https://doi.org/10.1016/j.jastp.2007.12.003.

Curto JJ, Castell J, Del Moral F. 2016a. Sfe: Waiting for the big one. J Space Weather Space Clim 6: A23. https://doi.org/10.1051/swsc/ 2016018

Curto JJ, Alberca LF, Castell J. 2016b. Dynamic aspects of the solar flare effects and their impact in the detection procedures. $J I G U$ Spec 2: 99-104.

Curto JJ, Marsal S, Creci G, Domingo G. 2017. Automatic detection of Sfe: A proposal. Ann Geophys 35: 799-804. https://doi.org/ 10.5194/angeo-35-799-2017.

Curto JJ, Marsal S, Blanch E, Altadill D. 2018. Analysis of the solar flare effects of 6 September 2017 in the ionosphere and in the Earth's magnetic field using spherical elementary current systems. Space Weather 16: 1709-1720. https://doi.org/10.1029/2018SW001927. 
Curto JJ, Juan JM, Timoté C. 2019. Confirming geomagnetic Sfe by means of a solar flare detector based on GNSS. J Space Weather Space Clim 9: A42. https://doi.org/10.1051/swsc/2019040.

Das Gupta MK, Sarkar SK. 1971. Some studies on geomagnetic crochet-associated solar optical flares and microwave bursts. $J R$ Astron Soc Can 65: 66-72.

Dellinger JH. 1935. A new radio transmission phenomenon. Phys Rev 48: 705.

Dellinger JH. 1937. Sudden ionospheric disturbances. Terr Mag Atmos Elec 42: 49-53.

Deshpande SD, Subramanyam CV, Mitra AP. 1972. Ionospheric effects of solar flares. J Atmos Terr Phys 34: 211-281.

Dieminger W, Geisweid KH. 1950. Solare und terrestriche beobachtugen während des Mögel-Dellinger-Effektes. J Atmos Terr Phys 1: $37-48$.

Dodson HW, Hedeman ER. 1958. Crochets-associated flares. Astrophys $J$ 128: 636-645.

Donnelly RF. 1976. Empirical models of solar flare X-ray and EUV emission for use in studying their $\mathrm{E}$ and $\mathrm{F}$ region effects. J Geophys Res 81: 4745-4753.

Dymek MK. 1989. Photochemical model of ion composition and electron density in the terrestrial ionosphere between 70 and 300 km. R Belgium Meteorol Inst Publ A120: 1-54.

Eleman F. 1961. On solar flares and geomagnetic solar flare effects (Sfe). Arkiv för Astronomi 3: 37-49.

Fleming JA. 1936. Notes on radio fade out of August 25, 1936. Terr Mag Atmos Elec 41: 404-406.

Friedman H, Chubb TA. 1954. The physics of the ionosphere. Physical Society, London.

Friedman H, Lichtman SW, Byram ET. 1951. Photon counter measurements of solar X-ray and extreme ultraviolet light. Phys Rev 83: 1025-1030.

García-Rigo A, Hernández-Pajares M, Juan JM, Sanz J. 2007. Solar flare detection system based on global positioning system data: First results. Adv Space Res 39(5): 889-895. https://doi.org/ 10.1016/j.asr.2006.09.031.

Gavrilov BG, Lyakhov AN, Poklad YV, Rybakov VA, Ryakhovsky IA, Loseva TV. 2018. Geophysical effects of solar flare on 6 September 2017. In: Proc. SPIE 10833, 24th International Symposium on Atmospheric and Ocean Optics: Atmospheric Physics, 1083397 (13 December 2018). https://doi.org/10.1117/12.2502477.

Gaya-Piqué LR, Curto JJ, Torta JM, Chulliat A. 2008. Equivalent ionospheric currents for the 5 December 2006 solar flare effect determined from spherical cap harmonic analysis. J Geophys Res 113: A07304. https://doi.org/10.1029/2007JA012934.

Gopalswamy N, Barbieri L, Cliver EW, Lu G, Plunkett SP, Skoug M. 2005. Introduction to violent Sun-Earth connection events of October-November 2003. J Geophys Res 110: A09S00. https://doi.org/10.1029/2005JA011268.

Grafe A. 1958. Untersuchungen fiber die geomagnetischen Sonneneruptions effekvteo n Postdam-Niemegkff ir die Periode 1890-1956. GeomagnI nst Posdam Abh 21: 9-43.

Greenfield SM, Venkateswaran SV. 1968. The vertical structure of the dynamo winds deduced from geomagnetic variations associated with solar flares. Ann Geophys 24: 665-672.

Heaviside O. 1902. Telegraphy, sect. 1, theory. Encyc Brit 10th Lond 9: $213-218$.

Hedin AE. 1987. MSIS-86 thermospheric model. J Geophys Res 92: 4649-4662.

Heroux L, Cohen M, Higgins JE. 1974. Electrondensities between 110 and $300 \mathrm{~km}$ derived from solar EUVfluxes of August 23, 1972. J Geophys Res 79: 5237-5244.
Hodgson R. 1860. On a curious appearance seen in the Sun. Month Notic Roy Astron Soc 20: 15-16. https://doi.org/10.1093/mnras/ 20.1.15.

IAGA Bulletin. 1954-1990. Bulletin 12i-12x: 32a-32p.

IAGA. 1959. Provisional atlas of rapid variations. Ann Int Geophys Yr II B: 668-709.

Imamiti S. 1938. Variations of the earth magnetic field observed during so-called Dellinger effect of radio waves. Mem Kakioka Magn Observ I: 13-19.

Imamiti S. 1940. Dellinger effect and variation of the earth's magnetic field. Mem Kakioka Magn Observ III: 21-22.

Kato Y, Tamao T, Saito T. 1959. Geomagnetic pulsation accompanying the intense solar flare. J Geomagn Geoelectr 10: 203-207.

Kennelly AE. 1902. On the elevation of the electrically-conducting strata of the earth's atmosphere. Electr World Eng 32: 473.

Kiplinger AL, García HA. 2004. Soft X-ray parameters of the greatflares of active region 486. Bull Am Astron Soc 36(739): 2004.

Kuwashima M, Uwai T. 1985. Solar flare effects on the magnetic variations. Mem Kakioka Magn Obs 21(1): 1-14.

Maple E, Bowen WA, Singer SF. 1950. Measurements of the earth's magnetic field at high altitudes at White Sands, New Mexico. J Geophys Res 55: 115-126. https://doi.org/10.1029/ JZ055i002p00115.

Marconi G. 1899. Wireless telegraphy. J Inst Elect Eng 28: 273-291.

Marsal S, Torta JM, Segarra A, Araki T. 2016. Use of spherical elementary currents to map the polar current systems associated with the geomagnetic sudden commencements on 2013 and 2015 St. Patrick's Day storms. J Geophys Res Space Phys 122: 194 211. https://doi.org/10.1002/2016JA023166.

Matsushita S, Campbell WH. 1967. Physics of geomagnetic phenomena. Academic Press, New York.

Mazaudier C, Blanc M. 1982. Electric currents above Saint-Santin, 2, model. J Geophys Res 87: 2465-2480.

McIntosh DH. 1951. Geomagnetic solar flare effects at Lerwick and Eskdalemuir, and relationship with allied ionospheric effects. $J$ Atmos Terr Phys 1: 315-342.

McNish AG. 1937a. Magnetic effects associated with bright solar eruptions and radio fade-outs. Nature 139: 244.

McNish AG. 1937b. Terrestrial Magnetic and ionospheric effects associated with bright chromospheric eruptions. Terr Magn Atm Elect 42(2): 109-122.

Meza A, Van Zele MA, Rovira M. 2009. Solar flare effect on the geomagnetic field and ionosphere. J Atmos Sol-Terr Phys 71: 1322-1332. https://doi.org/10.1016/j.jastp.2009.05.015.

Minnis CM, Bazzard GH. 1958. Solar flare effects in the F2 layer of the ionosphere. Nature 181(4610): 690-691.

Mitra SK. 1952. The upper atmosphere. The Asiatic Society, Calcutta.

Mögel H. 1930. Uber die Beziehungen zwischen Empfangsstorungen bei Kurzwellen und den Storungen de smagnetischen Feldes der Erde. Telefunken-Zeitung XI. Jg. (56): 14-31.

Nagata T. 1952. Characteristics of solar flare effects (Sqa) on geomagnetic field at Huancayo (Peru) and at Kakioka (Japan). $J$ Geophys Res 57: 1-14. https://doi.org/10.1029/JZ057i001p00001.

Nagata T. 1966. Solar flare effect on the geomagnetic field. $J$ Geomagn Geoelectr 18(2): 197-219.

Newton HW. 1946. Geomagnetic crochet occurrence at Abinger, 1936-46, and allied solar and radio data. Month Notic Roy Astron Soc Geophys Suppl 5: 200-215.

Ohshio M. 1964. Solar flare effect on geomagnetic variation. J Radio Res Lab Jpn 11(58): 377-491. 
Ohshio M, Fukushima N, Nagata T. 1963. Solar flare effect on geomagnetic variation. Rep Ionosph Space Res Jpn 17: 77-114.

Ohshio M, Maeda R, Sakagami H. 1966. Height distribution of local photoionization efficiency. J Radio Res Lab Jpn 13: 245-252.

Oliver WL. 1975. Models of Fl-region ion composition variations. J Atmos Terr Phys 37: 1065-1076.

Pintér S. 1967. Geomagnetic crochets of solar flares observed in Hurbanovo. Bull Astron Inst Czech 18: 274-281.

Pintér S. 1968. Solar flare X-ray emission producing geomagnetic pulsations. Bull Astron Inst Czech 19: 97-99.

Pintér S. 1969. The geomagnetic crochet of 7 July 1966. Ann IQSY 3: $209-214$.

Pratap R. 1957. The effect of solar flares on geomagnetic field. $J$ Geophys Res 62(4): 581-588.

Princep JM. 1947. Las fulguraciones cromos féricas y sus efectos inmediatos sobre el campo magnético terrestre. Urania 32: 1-39.

Rangarajan GK, Rastogi RG. 1981. Solar flare effects in equatorial magnetic field during morning counter electrojet. Ind $J$ Radio Space Phys 10: 190-192.

Rastogi RG. 2001. Electromagnetic induction due to solar flares at equatorial stations. J Atmos Sol-Terr Phys 63: 599. https://doi.org/ 10.1016/S1364-6826(00)00253-4.

Rastogi RG. 2003. Effect of a solar disturbances on the geomagnetic $\mathrm{H}, \mathrm{Y}$ and $\mathrm{Z}$ fields in American equatorial electrojet stations: Solar flare effects. J Ind Geophys Union 7(2): 43.

Rastogi RG, Kaushika ND, Trivedi NB. 1965. Solar flare crochet and sudden commencement in $\mathrm{H}$ within the equatorial electrojet region. J Atmos Terr Phys 27: 663-668. https://doi.org/10.1016/ 0021-9169(65)90135-2.

Rastogi RG, Deshpande MR, Sastri NS. 1975. Solar flare effects in equatorial counter electrojet currents. Nature 258: 218-219. https://doi.org/10.1038/258218a0.

Rastogi RG, Pathan BM, Rao DRK, Sastry TS, Sastri JH. 1999. Solar flare effects on the geomagnetic elements during normal and counter electrojet periods. Earth Planets Space 51(947-957): 1999. https://doi.org/10.1186/BF03351565.

Richmond AD, Venkateswaran SV. 1971. Geomagnetic crochets and associated ionospheric current systems. Radio Sci 6: 139-164. https://doi.org/10.1029/RS006i002p00139.

Rikitake T. 1950. Electromagnetic induction by magnetic variations connected with solar eruption. Bull Earthquake Res Inst Tokyo 28: 219-283.

Rikitake T, Yukutake T. 1962. A theory of Sfe current systems. J Atmos Terr Phys 24: 93-105. https://doi.org/10.1016/0021-9169 (62)90188-5.

Riley P. 2012. On the probability of occurrence of extreme space weather events. Space Weather 10: S02012. https://doi.org/ 10.1029/2011SW000734.

Romañá A. 1959. Report general with the provisional atlas of rapid variations. Ann Int Geophys $\operatorname{Yr}$ 2B: 668-709.

Roy M. 1977. Mutual induction between the E and D layers of the ionosphere during a solar flare. J Atmos Terr Phys 39: 221-227. https://doi.org/10.1016/0021-9169(77)90115-5.

Roy M. 1979. A two-layer model for the geomagnetic crochet. J Atmos Terr Phys 41: 225-229. https://doi.org/10.1016/00219169(79)90015-1.

Ruzmaikin A, Feynman J, Jun I. 2011. Distribution of extreme solar energetic proton fluxes. J Atmos Sol-Terr Phys 73: 300-307. https://doi.org/10.1016/j.jastp.2009.12.016.

Sastri JH. 1975a. Geomagnetic solar flare effect in the dark hemisphere. Ind J Radio Space Phys 4/3: 225-227.

Sastri JH. 1975b. Night time geomagnetic effects of solar flares. Ann Geophys 1/3: 389-394.
Sastri JH. 1975c. The geomagnetic solar flare effect of 6 July 1968 and its implications. Ann Geophys 31/4: 481-485.

Sastri JH. 1977. Nature of crochet associated solar microwave bursts. Ind J Radio Space Phys 6: 184-185.

Sastri JH, Murthy BS. 1975a. On the relations between Sfe (crochet) and solar X-ray and microwave bursts. Sol Phys 41: 477-485. https://doi.org/10.1007/BF00154084.

Sastri JH, Murthy BS. 1975b. Geomagnetic effect associated with X-ray flare from Sco X-1. Nature 257: 35-36.

Sastri JH, Murthy BS. 1975c. Geomagnetic effects in the dark hemisphere associated with solar flares. J Geomagn Geoelectr 27 $67-73$.

Sastri JH, Murthy BS, Karunakaran D. 1975. Geomagnetic crochets associated with proton flares. Ind J Radio Space Phys 4-1: 89-92.

Selvakumaran R, Mauryab AK, Gokania SA, Veenadharia B, Kumarc S, Venkateshamb K, Phanikumard DV, Singhe AK, Siinghf D, Singhb R. 2015. Solar flares induced D-region ionospheric and geomagnetic perturbations. J Atmos Sol-Terr Phys 123: 102-112. https://doi.org/10.1016/j.jastp.2014.12.009.

Singer SF, Maple E, Bowen WA. 1951. Evidence for ionospheric currents from rocket experiments near the geomagnetic equator. J Geophys Res 56: 265-281. https://doi.org/10.1029/ JZ056i002p00265.

Siscoe GL, Formisano V, Lazarus AJ. 1968. Relation between geomagnetic sudden impulses and solar wind pressure changes an experimental investigation. J Geophys Res 73(15): 4869-4874. https://doi.org/10.1029/JA073i015p04869.

Srivastava BJ. 1974. The geomagnetic solar flare effect of 3 May 1973 at Indian stations and its dependence on the counter electrojet. J Atmos Terr Phys 36: 1571-1575. https://doi.org/ 10.1016/0021-9169(74)90236-0.

Srivastava BJ, Abbas H. 1975. Nighttime geomagnetic solar flare effect. Ind J Radio Space Phys 4: 102-103.

Stewart B. 1861. On the great magnetic disturbance which extended from August 28 to September 7, 1859, as recorded by photography at the Kew Observatory. Philos Trans $R$ Soc Lond 151: 423-430.

Stubbe P. 1968. Frictional forces and collision frequencies between moving ion and neutral gases. J Atmos Terr Phys 30: 1965-1985.

Subrahmanyan RV. 1964. Geomagnetic effects associated with relativistic flares. J Atmos Terr Phys 26: 1119-1126. https://doi. org/10.1016/0021-9169(64)90098-4.

Tanskanen EI, Viljanen A, Pulkkinen TI, Pirjola R, Häkkinen L, Pulkkinen A, Amm O. 2001. At substorm onset, 40\% of AL comes from underground. J Geophys Res 106(A7): 13119-13134. https://doi.org/10.1029/2000JA900135.

Thomson NR, Rodger CJ, Dowden RL. 2004. Ionosphere gives size of greatest solar flare. Geophys Res Lett 31: L06803. https://doi. org/10.1029/2003GL019345.

Thomson NR, Rodger CJ, Clilverd MA. 2005. Large solar flares and their ionospheric D region enhancements. J Geophys Res 110: A06306. https://doi.org/10.1029/2005JA011008.

Thomson AWP, Dawson EB, Reay SJ. 2011. Quantifying extreme behavior in geomagnetic activity. Space Weather 9: S10001. https://doi.org/10.1029/2011SW000696.

Tsurutani BT, Verkhoglyadova OP, Mannucci AJ, Lakhina GS, Li G, Zank GP. 2009. A brief review of "solar flare effects" on the ionosphere. Radio Sci 44: RS0A17. https://doi.org/10.1029/ 2008RS004029.

Van Sabben D. 1961. Ionospheric current systems of ten IGY solar flare effects. J Atmos Terr Phys 22: 32-42. https://doi.org/10.1016/ 0021-9169(61)90175-1. 
Van Sabben D. 1968. Solar flare effects and simultaneous magneticdaily variation. J Atmos Terr Phys 30: 1641-1648. https://doi. org/10.1016/0021-9169(68)90012-3.

Van Zele MA, Meza A. 2011. The geomagnetic solar flare effect identified by SIIG as an indicator of a solar flare observed by GOES satellites. Adv Space Res 48: 826-836. https://doi.org/ 10.1016/j.asr.2011.04.037.

Veldkamp J, Van Sabben D. 1960. On the current system of solar flare effects. J Atmos Terr Phys 18: 192-202.
Villante U, Regi M. 2008. Solar flare effect preceding Halloween storm (28 October 2003): Results of a worldwide analysis. $J$ Geophys Res 113: A00A05. https://doi.org/10.1029/ 2008JA013132.

Volland H, Taubenhein J. 1958. On the ionospheric current system of the geomagnetic solar flare effect (sfe). J Atmos Terr Phys 12: 258-265.

Yasuhara M, Maeda H. 1961. Geomagnetic crochet of 15 November 1960. J Atmos Terr Phys 21: 289-293.

Cite this article as: Curto JJ. 2020. Geomagnetic solar flare effects: a review. J. Space Weather Space Clim. 10, 27. 